\title{
最適化手法を用いた大規模管網系の定常流解析 \\ OPTIMIZATION TECHNIQUE FOR SOLVING STEADY FLOWS IN LARGE NETWORK PIPE SYSTEMS
}

\author{
島田正志* \\ By Masashi SHIMADA
}

\begin{abstract}
This paper deals with the loop analysis for efficiently solving the steady flow in large pipe network system. (1) The analysis having not flow rates through co-trees but around loops (or meshes) as independent variables is graph-theoretically formulated. (2) The calculation algorithm using the conjugate gradient method is shown to solve the nonlinear optimization problem based on the principle of minimum dissipative energy. (3) For practical and efficient calculations of sparse matrices how to number nodes, trees, and fundamental loops is made clear. And (4) the method due to the minimization is compared with other excellent methods based on the Newton-Raphson algorithm.
\end{abstract}

\section{1. まえがき}

パイプラインの設計には, 設計流量を対象とした最適 設計とその定常流解析が不可欠である. システムの制御 管理上，設計流量より少ない種々の流量に対する解析も 同様である1). 本論文では，大規模管網系を対象として， 流量法による定常流解析を取り扱う。流量法は，独立な 各閉路に対応する補木流量 ${ }^{2)}$, あるいは, Mesh 流量 ${ }^{3)}$ (閉 路の代表流量 $\left.{ }^{4)}\right)$ のいずれを独立変数とするかで, 補木 流量法, Mesh 流量法に区分できる. システムの有向グ ラフ中で閉路の取り方は数多くある. 基本閉路として, 内部に木および補木を全く有しない閉路 (自然な閉路 ${ }^{5)}$ ) をとれば, Mesh 流量法の場合, Newton-Raphson 法 (NRM) のヤコビ係数行列は正定値対称・対角優位な 疎行列となり, 優れた解法 (SOR, 還元解法 ${ }^{5), 6)}$, 対称 疎行列性を利用したガウス法 ${ }^{3), 9)}$ 等）がある.

一方，閉路エネルギーベクトルの 2 乗和を目的関数之 する最小化原理に基づく解法 ${ }^{81}$, 否定的に知られてい る7). また, 管網系では, より自然な変分原理が存在し, 計算手法への適用が試みられている.この変分原理の定 式化は, 線形電気回路における “Minimum Heat

* 正会員 農博 研究員 農業土木試験場 （₹ 305 茨城県筑波郡谷田部町観音台 2-1-2)
Theorem”の発見に始まり ${ }^{10)}$ ，非線形回路でキルヒホフ 則の成立時には“Content”あるいは“Co-content”な る量が定常状態で停留值となることが示された ${ }^{11)}$. Birkoff らは, 定常流解析をポテンシャル境界值問題との 類似より，(1) Dirichle 問題（節点エネルギーが既知）, (2) Neumann 問題（節点境界流入流量が既知，(3) 混合 型問題, と分類し, 各夕イプに対して変分問題として定 式化を行ったうえで，きわめて一般的条件下で解の存在 と一意性を証明した ${ }^{12)}$.さらに, Brayton と Moser は, 非線形電気回路系の非定常問題で, “Mixed Potential” が停留值をとるとき定常状態となることを示し ${ }^{13)}$, 鬼塚 は水理的非線形系へその考え方を適用した ${ }^{14), 15)}$. 以上の 定常流に関する変分原理を数值解法として応用したの は, Collins とCooper である ${ }^{16)}$. しかし, 疎行列性の 利用, ベクトル演算による必要配列数の削減等の工夫に より，計算効率を高めたうえで実用上の解法として評価 がなされたとはいいがたい.

本論文では，(1) 補木流量法から Mesh 流量法への変 換をグラフ理論で明確な定式化を行い，(2) 散逸エネル ギーの最小化原理を利用し，共役勾配法による計算アル ゴリズムを示す. (3)さらに, 効率的疎行列演算を行う ために，グラフ作成手順とデータの与え方を整理し，具 体例に基づいて実際の計算の指針を与え, (4) 最後に, 
提示した解法と既存の解法の数值例による比較を行う.

\section{Neumann 問題に対する閉路解析}

\section{（1）基礎方程式}

大規模管網系を対象とする定常流解析を系統的に取り 扱うために，系の有向グラフを定義し，木（Tree），補 木·(Co-tree), および, 補木に対応する基本閉路を定める. グラフ理論の定式化により ${ }^{17), 18)}$ ，節点で流量式，基本閉 路の水頭エネルギー連続式，および，節点水頭を定める 式は,

$$
\begin{aligned}
& A \boldsymbol{q}=\boldsymbol{Q} \\
& B \boldsymbol{H}=\boldsymbol{O} \\
& A^{*} \boldsymbol{\Phi}=\boldsymbol{H}
\end{aligned}
$$

ここで, $A(N S, N P)=$ 既約接続行列, $B(N G, N P)=$ 基 本閉路行列, $\boldsymbol{H}(N P)=$ 管路に対する損失水頭ベクトル $(\mathrm{m}), \boldsymbol{q}(N P)=$ 管路の流量ベクトル $\left(\mathrm{m}^{3} / \mathrm{s}\right), \boldsymbol{Q}(N S)=$ 節点での境界流入ベクトル $\left(\mathrm{m}^{3} / \mathrm{s}\right), \boldsymbol{\Phi}(N S)=$ 基準節点 に相対的な節点水頭ベクトル $(\mathrm{m}), A^{*}=A$ の転置行列, $N P=$ 管路総数, $N S=$ 節点総数 $-1, N G=$ 独立基本閉 路の個数で,

$$
N G=N P-N S
$$

基準節点の流量式は，他の節点の流量式と一次従属関 係にあるので, 基準節点 $(N S+1$ 番目の節点で水頭を ゼロとする）を除外した既約接続行列 $A=\left\{a_{i j}\right\}$ は,

$$
a_{i j}=\left\{\begin{array}{c}
+1: \text { 管路 } j \text { が節点 } i \text { を始点とするとき } \\
-1: \text { 管路 } j \text { が節点 } i \text { を終点とするとき } \\
0: \text { 管路 } j \text { が節点 } i \text { と接続しないとき }
\end{array}\right.
$$

$B=\left\{b_{l j}\right\}$ は

$$
b_{l j}=\left\{\begin{array}{l}
+1: \text { 管路 } j \text { が閉路 } l \text { に同一方向に含まれるとき } \\
-1: \text { 管路 } j \text { が閉路 } l \text { に逆向きに含まれるとき } \\
0: \text { 管路 } j \text { が閉路 } l \text { に含まれないとき }
\end{array}\right.
$$

管路番号は，木 $(1,2, \cdots, N S)$ および補木 $(N S+1$, $N S+2, \cdots, N P)$ とする．節点，管路，および，閉路の 番号づけの方法は, 疎行列 $A, B$ を非ゼロ要素表で表

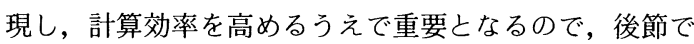
詳述する。

\section{（2）補木流量法, Mesh 流量法}

$A, B, \boldsymbol{q}$, および, $\boldsymbol{H}$ の木・補木に対応する表現を $\left(A_{T}\right.$, $\left.A_{c}\right),\left(B_{T}, B_{c}\right),\left(\boldsymbol{q}_{T}^{*}, \boldsymbol{q}_{c}^{*}\right)^{*}$, および, $\left(\boldsymbol{H}_{T}^{*}, \boldsymbol{H}_{c}^{*}\right)^{*}$ と する. 式 (1)，(2)は,

$$
\begin{aligned}
& A_{T} \boldsymbol{q}_{T}+A_{c} \boldsymbol{q}_{c}=\boldsymbol{Q} \\
& B_{T} \boldsymbol{H}_{T}+B_{c} \boldsymbol{H}_{C}=\boldsymbol{O}
\end{aligned}
$$

補木流量法では $B_{C}=I_{C}(N G$ 次単位行列) となるよう閉 路をとるが，一般には， $A$ と $B^{*}$ の直交性より

$$
B_{T}^{*}=-A_{T}^{-1} A_{c} B_{C}^{*}
$$

ここで, $A_{T}^{-1}=A_{T}$ の逆行列

Mesh 流量法では，基本閉路を “自然な閉路”にとり，
補木流量 $\boldsymbol{q}_{c}$ に代わり Mesh 流量 $\boldsymbol{q}_{c}^{\prime}$ を次式で導入する.

$$
\boldsymbol{q}_{c}=B_{c}^{*} \boldsymbol{q}_{c}^{\prime}
$$

ここで， $\boldsymbol{q}_{c}^{\prime}=$ 高桑が “要素閉管路の代表流量” とした 量で ${ }^{4), 6)}$, 本解析で独立変数の役割を果たす.

以上の式より，木流量は次式で与えられる.

$$
\begin{aligned}
& \boldsymbol{q}_{T}=B_{T}^{*} \boldsymbol{q}_{c}^{\prime}+\boldsymbol{R} . \\
& \boldsymbol{R}=A_{T}^{-1} \boldsymbol{Q} \cdots \cdots
\end{aligned}
$$

損失水頭ベクトルは, 経験公式を一般化して

$$
\boldsymbol{H}=\left\{H_{i} \mid=\left\{F_{i} q_{i}\left|q_{i}\right|^{m}\right\}\right. \text {. }
$$

ここで, $F_{i}=$ 管径, 抵抗係数を含む一般化した抵抗係数, $m=$ 指数.

$\boldsymbol{q}_{c}^{\prime}$ は, 式（6)，（7)，（8），(10）の非線形連立方 程式の解となる. $\boldsymbol{\Phi}$ は, 式 ( 7 ), （8）より $\boldsymbol{q}_{c}, \boldsymbol{q}_{r}$, 式 (10) より $\boldsymbol{H}$ を求め, 次式で定まる.

$$
\boldsymbol{\Phi}=\left(A_{T}^{*}\right)^{-1} \boldsymbol{H}_{T}
$$

\section{（3）散逸エネルギーの最小化原理}

定常解が変分最小化問題と等価であることを平易に示 す.

$$
\int(B \boldsymbol{H})^{*} d \boldsymbol{q}_{c}^{\prime}=0^{12), 16)}
$$

すなわち，成分表示で和の順序を交換すると，

$$
\begin{aligned}
& \int \sum_{j=1}^{N S} F_{j} q_{j}\left|q_{j}\right|^{m}\left(\sum_{i=N S+1}^{N P} b_{i j} d q_{i}^{\prime}\right) \\
& \quad+\sum_{l=N S+1}^{N P} F_{l} q_{l}\left|q_{l}\right|^{m}\left(\sum_{i=N S+1}^{N P} b_{i l} d q_{i}^{\prime}\right)=0
\end{aligned}
$$

$d \boldsymbol{q}_{T}=B_{T}^{*} d \boldsymbol{q}_{c}^{\prime}, d \boldsymbol{q}_{c}=B_{c}^{*} d \boldsymbol{q}_{c}^{\prime}$ であるので，上式を積分し てポテンシャル $P$ を得る.

$$
P=\frac{1}{(m+2)} \sum_{i=1}^{N P} F_{j} q_{j}\left|q_{j}^{2}\right|^{m}=\mathrm{const}
$$

$P$ を $\boldsymbol{q}_{c}^{\prime}$ で偏微分したポテンシャル勾配は,

$$
\nabla P=\frac{\partial P}{\partial \boldsymbol{q}_{c}^{\prime}}=B \boldsymbol{H}=\mathbf{0}
$$

式（13）は $P$ の停留性を示す．次に, $\nabla^{2} P$ の正定值性 を示す.

$$
\nabla^{2} P=\left\{\frac{\partial^{2} P}{\partial q_{l+N S}^{\prime} \partial q \frac{\prime}{\imath}+N S}\right\}=(m+1) \sum_{j=1}^{N P} b_{l j} b_{\bar{l} j} F_{j}\left|q_{j}\right|^{m}
$$

ゆえに

$$
\left(d \boldsymbol{q}_{c}^{\prime}\right)^{*} \nabla^{2} P\left(d \boldsymbol{q}_{c}^{\prime}\right)=\sum_{j=1}^{N P} F_{j}\left|q_{j}\right|^{m}\left(d q_{j}\right)^{2}>0
$$

$P$ は power の次元を有し, 誘導した関係式は, 単位 時間当たりの管路の散逸エネルギーが最小となるときに 定常状態が実現するという意味で, 自然界の目的原理を 反映する.

\section{（4）非線形最適化問題の数值解法}

前節までの議論より，定常流解析を線形制約つき非線 形最小化問題に変換する.

$\operatorname{minimize}\left(P\left(\boldsymbol{q}_{c}^{\prime}\right)\right): \boldsymbol{q}_{c}=B_{c}^{*} \boldsymbol{q}_{c}^{\prime}$

$$
\boldsymbol{q}_{T}=B_{T}^{*} \boldsymbol{q}_{c}^{\prime}+\boldsymbol{R}
$$


以下に，共役勾配法 (Conjugate gradient method) を 利用した計算方法について述べる.

a) 初期値設定

NRM では, 適切な初期値の設定が本質的に重要であ る.ここでも，抵抗項を線形近似して ${ }^{19)}$

$\boldsymbol{H}=\left\{F_{i} q_{i}\right\}$

第一近似解を次式より求める.

$S \boldsymbol{X}=\boldsymbol{b}$

$S=B F B^{*}, \quad F=\operatorname{diag}\left(F_{1}, F_{2}, \cdots, F_{N P}\right), \quad \boldsymbol{b}=-B_{T} F_{T} \boldsymbol{R}$, $F_{T}=\operatorname{diag}\left(F_{1}, F_{2}, \cdots, F_{N S}\right)$

行列 $S$ は, NRM のヤコビ係数行列と同一の性質を有 し，正定值対称疎行列であり，非ゼ口要素表を作成すれ ば, Hestenes-Stiefel 法で効率的に計算できる ${ }^{20)} . \boldsymbol{R}$ は, 節点, 木の番号づけを工夫して代数的に求め得る (後述).

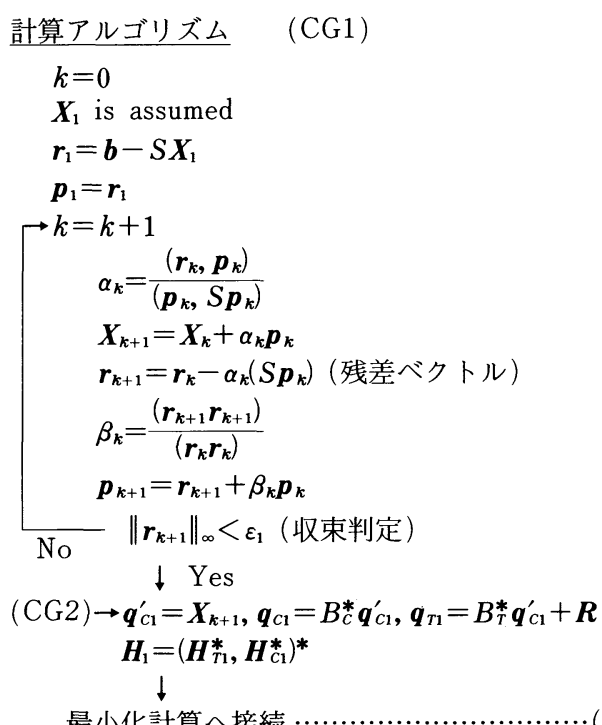

最小化計算へ接続

収束判定は, 残差べクトル $\boldsymbol{r}_{\boldsymbol{k}+1}$ のノルムで行うが, 制御変数 $\varepsilon_{1}$ を小さくとりすぎないよう注意すべきであ る.

b）最小化計算アルゴリズム

$\boldsymbol{q}_{c}\left(\boldsymbol{q}_{c}^{\prime}\right), \boldsymbol{q}_{T}\left(\boldsymbol{q}_{c}^{\prime}\right)$ であるので簡約勾配法が適用でき ${ }^{21)}$, $P$ の值を降下させる $\boldsymbol{q}_{C}^{\prime}$ の方向ベクトルを $\boldsymbol{p}$, 同様に $\boldsymbol{q}_{T}$, $\boldsymbol{q}_{c}$ の方向ベクトル $\boldsymbol{p}_{T}, \boldsymbol{p}_{c}$ を求め, Fletcher-Reeves 法 で収束条件が満足されるまで降下を繰り返すＰ $P$ 值 を最小とする方向ベクトルの長さ $\alpha$ は, 三次多項式補 間を利用した一次元探索で決定する ${ }^{21), 221}$. なお, 初期值 を式（18）で行う解法を（CG 1), 任意の初期值より最 小化計算する解法を（CG 2）と略記する.

$$
\begin{aligned}
& \text { 計算アルゴリズム } \\
& k=0 \\
& \boldsymbol{g}_{1}=B \boldsymbol{H}_{1}=\left(\boldsymbol{E}_{1}\right) \text { (誤差ベクトル) } \\
& \beta_{1}=0
\end{aligned}
$$

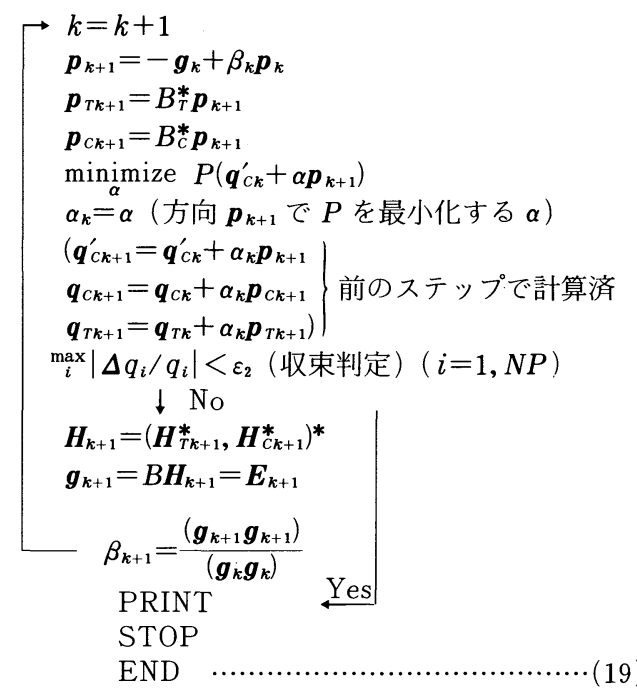

誤差ベクトル $\boldsymbol{E}=B \boldsymbol{H}$ の 2 乗ノルムを目的関数とす る最小化法 $(\mathrm{CRM})$ も知られている ${ }^{8)}$.

$$
\begin{aligned}
& \bar{P}=(B \boldsymbol{H})^{*}(B \boldsymbol{H}) \\
& \frac{\partial \bar{P}}{\partial \boldsymbol{q}_{c}^{\prime}}=2 S^{\prime} B \boldsymbol{H} .
\end{aligned}
$$

ここで, $S^{\prime}=B \tilde{F} B^{*}, \tilde{F}=\operatorname{diag}\left(F_{1}\left|q_{1}\right|^{m}, F_{2}\left|q_{2}\right|^{m}, \cdots\right.$, $\left.F_{N P}\left|q_{N P}\right|^{m}\right), \quad S^{\prime}$ はNRM のヤコビ係数行列である. 定 常解は, $\bar{P}=0$ を満足する. この解法は, 綾により実用 上の価值がないと評価された7).

\section{（5）疎行列性利用による計算の効率化とグラフ作成 手順}

ここでは，2.（1）で述べた視点より，グラフ作成手 順を整理し明確にしたうえで, Fig. 1 のシステム 1 (NP $=18, N S=12, N G=6$, 基準節点は節点 13 , 木 (1 12), 補木 $(13 \sim 18)$, 基本閉路は節点番号を閉路の方向に沿っ

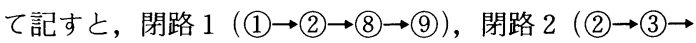

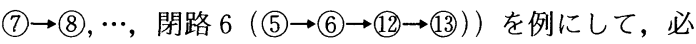
要となるデータの非ゼロ要素表を作成する.

\section{a) 既約接続行列 $A$}

$A_{T}^{-1},\left(A_{T}^{*}\right)^{-1}$ が， $\boldsymbol{R}, \boldsymbol{\Phi}$ を知るうえで既知でなければ ならない, 一般に, 逆行列を計算すれば, 計算精度, 効 率に影響する. そこで, 節点・木の番号づけを工夫して, この労力を軽減する. 基準節点より，すべての木と節点 を順次通る 1 本の経路を “1 筆書き” の要領で作成する. 次に, 節点番号を基準節点より, 順次 $(N S, N S-1$,

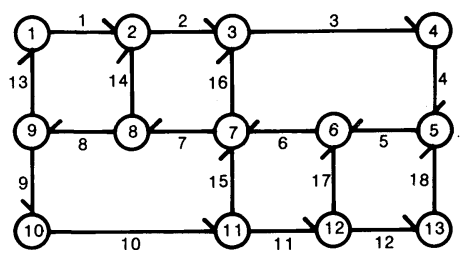

Fig. 1 System 1. 
$\cdots, 2,1)$ で与え, 木番号は, 節点 $i$ から節点 $(i+1)$ へ 向かう経路を木番号 $i$ とする. この方法により， $A_{T}$ は, 式 (22) のように, 対角成分が+1, その 1 段下がー1, およびそれ以外はすべてゼロ要素となる， $A_{T}^{-1}$ も一般性 を失うことなく, 式 (23) で与えられる.

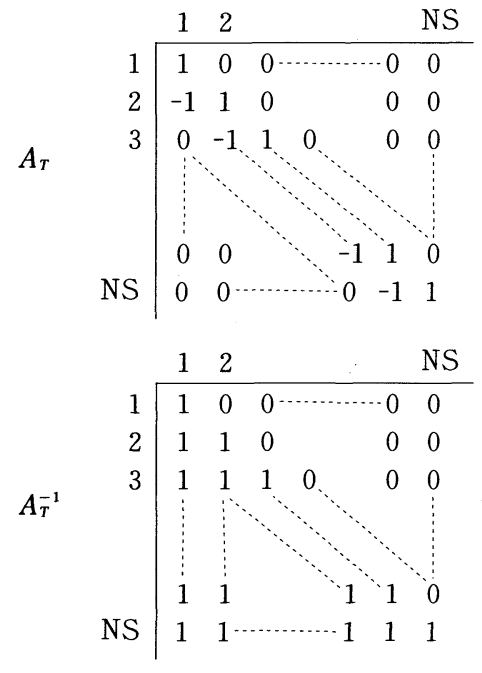

式（23）より $\boldsymbol{R}, \boldsymbol{\Phi}$ は, 行列計算するまでもなく, 代数計算で容易に求め得る. 高桑は, $\boldsymbol{q}_{c}^{\prime} よ り \boldsymbol{q}_{T}$ を求め る際に, “管路 $l$ の流量＝(その下流側にあるすべての節 点流出水量の和 $)$-(その下流側にある節点への連結管路 流量の和)” と定式化した ${ }^{6)}$. 式 (23) は, 節点流出水 量の総和はゼロであるので, 高桑の定式化 (上三角行列 $\left(A_{T}^{-1}\right)^{*}$ 之一致) の相補的表現に対応する. 結論的に $A_{T}$, $A_{c}$ のデー夕は不必要である.

\section{b) 基本閉路行列 $B$}

基本閉路は，自然な閉路と定めた。閉路の番号づけは 木または補木を境界として接する閉路ざうしの番号の差 がヤコビ係数行列の帯幅に影響するので，この差を小さ くすべきである ${ }^{5}$. 基本閉路行列 $B$ の非ゼ口要素表の作 成法は，任意の木または補木は多くても2つの基本閉路 に属するのみであるから, 列番号を木または補木の番号 にとり，列ベクトルに 2 個の州属する閉路番号を記憶さ せて行う， $B_{T}, B_{c}$ に対応する非ゼ口要素表を NBT $(2$, $N S), N B C(2, N G)$ で与えれば, Fig.1のシステム の場合,

NBT

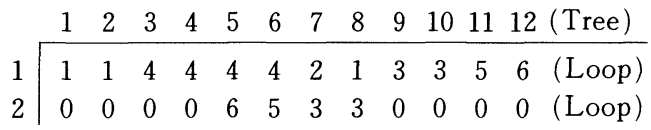

NBC

$$
\begin{array}{l|ccccccc}
13 & 14 & 15 & 16 & 17 & 18 & \text { (Co-tree) } \\
\cline { 2 - 7 } & 1 & 2 & 3 & 4 & 5 & 6 & \text { (Loop) } \\
2 & 0 & -1 & -5 & -2 & -6 & 0 & \text { (Loop) }
\end{array}
$$

負値は，閉路と木または補木の向きが逆であることを示 す。なお，閉路と対応する補木の向きは，同一方向に定 める. NBT により, $\boldsymbol{y}=B_{T}^{*} \boldsymbol{X}$ を非ゼ口要素を基本とし た演算で，次のようにサブ・ルーチン化できる.

FÕR J $=1$ TO NS : W=0 : FŌR L $=1$ TŌ $2: \mathrm{W}=$ $\mathrm{W}+\mathrm{SGN}(\operatorname{NBT}(\mathrm{L}, \mathrm{J})) * \mathrm{X}(\operatorname{ABS}(\operatorname{NBT}(\mathrm{L}, \mathrm{J})))$ : NEXT $L: Y(J)=W:$ NEXT J

$B_{T}^{*}, B_{c}^{*}$ の非ゼロ要素表 NBTT(LM, NG), NBCT(2, $N G$ ) (列番号＝閉路番号，列ベクトルに帰属する木ま たは補木の番号を記憶）から， $B_{T} X, B_{C} X$ の効率的演

\begin{tabular}{|c|c|c|c|c|c|c|c|}
\hline & 1 & 2 & 3 & 4 & 5 & & (Loop) \\
\hline 1 & 1 & 2 & 7 & 3 & 6 & & (Tree) \\
\hline 2 & 8 & 7 & 8 & 41 & 111 & & (Tree) \\
\hline 3 & 0 & 0 & 9 & 5 & 0 & ) & (Tree) \\
\hline & & 0 & 10 & 6 & & & (Tree) \\
\hline
\end{tabular}
算が可能である. LM は, 1 つの閉路に帰属する木の最 大個数である. NBTT, NBCT は, システム 1 に対して, NBTT

NBCT

\begin{tabular}{rrrrrrrr}
1 & 2 & 3 & 4 & 5 & 6 & (Loop) \\
\cline { 2 - 7 } & 13 & 14 & 15 & 16 & 17 & 18 (Co-tree) \\
2 & -14 & -16 & 0 & 0 & -15 & -17 (Co-tree)
\end{tabular}

表中のゼロは, ゼロ要素を意味するが, SGN (NBT) L, $\mathrm{J}))=0$ となるので, $\mathrm{X}(0)$ が許容されれば便利な表現 である.

（6） Newton-Raphson 法の計算アルゴリズム

最小化原理に基づく解法（CG 1，CG 2) を評価する ために，比較対象となる NRMによる諸解法について 述べる ${ }^{23)}$.

初期值設定は, 式 (17) で行う.これにより, その後 の求解過程は, 木・補木の選択に依存せず理論上同一と なる ${ }^{24)}$.

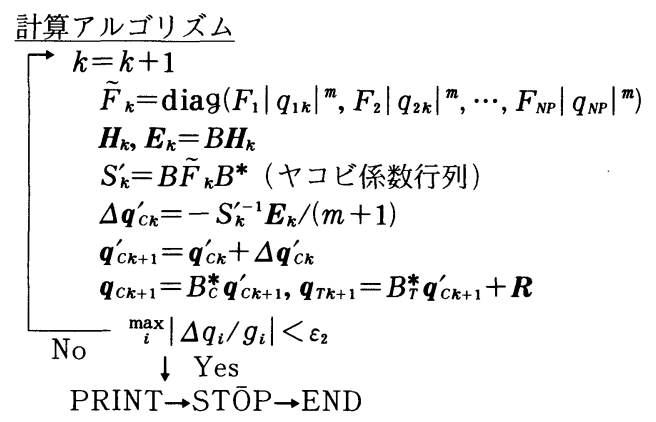

$k$ 回目の補正値 $\Delta \boldsymbol{q}_{c k}^{\prime}$ の解法として, (1) 対称性を利 用したガウス消去法 $(\mathrm{SYG})^{25)}$, (2) 還元解法 $(\mathrm{RDM})^{6}$, (3) 対称疎行列性を利用したガウス法 $(\mathrm{SPG})^{3), 9)}$, (4) SOR による反復解法 $(\mathrm{SOR})^{6)}$ ，等がある. どの解法で あれ， $S^{\prime}$ の非ゼ口要素表を作成すべきである， $S^{\prime}$ の非 
ゼロ要素は, 閉路 $i$ を $i$ 行に対応づけ，この閉路に木ま たは補木を共通境界として接する閉路を $j$ とすれば $(i$, $j ）$ 成分は非ゼロとなる，ある閉路が自身を含めて最大 IN 個の閉路と接するとすれば, NJACO (NG, IN) で 非ゼロ要素が表現できる. システム 1 では，IN=4で次 表となる.計算アルゴリズムの中に対称性を生かせれば, $1 / 2$ の要素数の計算で斉む. 本論文の計算結果は, SOR のみ対称性を利用していない.

$\mathrm{NJACO}$

\begin{tabular}{ll|lllll}
\multicolumn{1}{l}{} & \multicolumn{1}{l}{1} & 2 & 3 & 4 & (IN) \\
\cline { 2 - 7 } & 1 & 1 & 2 & 3 & 0 & \\
& \\
& 2 & 1 & 2 & 3 & 4 & \\
& 3 & 1 & 2 & 3 & 5 & \\
& 4 & 2 & 4 & 5 & 6 & \\
& 5 & 3 & 4 & 5 & 6 & \\
(NG) & 6 & 4 & 5 & 6 & 0 &
\end{tabular}

\section{（7） 解法の比較}

Fig. 2 に示すシステム $(\mathrm{NP}=157, \mathrm{NS}=87, \mathrm{NG}$ $=70)$ に対して, 境界流入ベクトル $\boldsymbol{Q}(\boldsymbol{Q}(4)=2.8$, $Q(41)=2.4, Q(48)=2.5, Q(84)=2.3$, その他 の節点で $Q=-10 / 84)$ を与え, 定常流解析を行い解法 の比較・検討をする.

各管路の一般的抵抗係数は, Table 1 に示す. 左から 右, 上から下へ $(J=1 \sim 157)$ に対応する.

Table 2 に流量ベクトル $\boldsymbol{q}$ の真值を示す. (SPG で $\varepsilon_{2}$ $=10^{-5}$ とした解).

Table 3 には, NRM の各解法で $\varepsilon_{2}=10^{-3}$ とした各計 算過程の時刻 $(\mathrm{T})$, ポテンシャル $(\mathrm{P})$, ポテンシャル 勾配 $(G)$ を示す.
Table 1 Friction Coefficients.

$F(J)(J=1, N P)$

$30.5 \#, 80.5 \#, 56.2 \#, 76.9 \#, 49.6 \#, 28,7 \#, 59.3 \#, 87.5 \#, 99.8 \#, 58.8 \#$ $82.4 \#, 74.5 \#, 55.6 \#, 38.4 \#, 57.8 \#, 30.6 \#, 48.4 \#, 63.4 \#, 78.5 \#, 67.5 \#$ 34. 5\#, 75. 4\#, 86, 5\#, 54. 8\#, 45. 8\#, 43. 2\#, 67, 5\#, 47. 5\#, 56. 6\#, 78. $4 \#$ $67.5 \#, 89.7 \#, 89.6 \#, 66,8 \#, 75,4 \#, 45,3 \#, 46,4 \#, 75,3 \#, 98,5 \#, 83,5 \#$ $29.8 \#, 38,5 \#, 58,5 \#, 45,7 \#, 68,9 \#, 76,9 \#, 55.8 \#, 65.4 \#, 79.8 \#, 63,4 \#$ 45. 8\#, 48. 5\#, 83. 4\#, 79. 3\#, 59. 1\#, 39. 7\#, 81. 6\#, 76. 4\#, 53, 2\#, $91.2 \#$ 34. $8 \#, 49.2 \#, 77.2 \#, 48.9 \#, 45,6 \#, 77.1 \#, 28.4 \#, 82.8 \#, 54.9 \#, 66.7 \#$ 49. $5 \#, 44.9 \#, 52.7 \#, 69.6 \#, 39.7 \#, 75.3 \#, 54.7 \#, 69.3 \#, 77,6 \#, 74.7 \#$ $88.6 \#, 76.5 \#, 69,6 \#, 54.8 \#, 76.2 \#, 46.9 \#, 38.7 \#, 30.7 \#, 87,4 \#, 52.7 \#$ $98.6 \#, 109.3 \#, 89.7 \#, 45,6 \#, 45.8 \#, 47,8 \#, 82.4 \#, 70,5 \#, 67,3 \#, 45.7 \#$ $55.7 \#, 87,4 \#, 65.8 \#, 88.9 \#, 37.8 \#, 73.6 \#, 38.5 \#, 88.2 \#, 86.4 \#, 76.4 \#$ $154.6 \#, 56.7 \#, 65.7 \#, 81.9 \#, 74.4 \#, 65.9 \#, 82.4 \#, 57,5 \#, 28.4 \#, 65.4 \#$ 47. $9 \#, 55.9 \#, 76.6 \#, 65.5 \#, 49.9 \#, 56.7 \#, 74.8 \#, 47.4 \#, 76.9 \#, 49.6 \#$ $56.9 \#, 38.5 \#, 59.2 \#, 87,4 \#, 65.5 \#, 87.5 \#, 59.6 \#, 58.9 \#, 59.2 \#, 63.4 \#$ $67,4 \#, 56,4 \#, 73,5 \#, 76.5 \#, 59.6 \#, 45,7 \#, 123,8 \#, 38,7 \#, 75,4 \#, 83,6 \#$ $58.9 \#, 66.8 \#, 49.3 \#, 54.6 \#, 74.5 \#, 79.6 \#, 39.6 \#$

Table 2 True Solution for Flow Rate Vector.

\begin{tabular}{|c|c|c|c|c|c|c|c|c|c|}
\hline & & & & & & & & & \\
\hline & -0.243 & & & & & & & & \\
\hline 141 & & & & & & & & & \\
\hline & & & & & & & & & \\
\hline & & & -0. & & & & & & \\
\hline & & 0.0 & & -0. & & & & & \\
\hline & & & & & & & & & \\
\hline & & & & & & & & & \\
\hline & & 0 . & & & & & & & \\
\hline & & & & & & & & & \\
\hline & 0 & -0. & & & & & & & \\
\hline & & & & & & & & & \\
\hline & & & & & & & & & \\
\hline & & & & & & & & & \\
\hline & & & & & & & & & \\
\hline & & & & 0.038 & 0.023 & 0.042 & & & \\
\hline
\end{tabular}

SOR の場合，加速パラメーター $\omega_{c}$ により収束性が 異なるが, Table 4 にその相異を示す. 補木流量法の場 合と異なり, Mesh 流量法では, SOR は優れた収束性 を示す. 最適加速パラメーターの決定を除けば, 手法の 容易さ, 配列容量, 等の点でも有利な手法 ${ }^{26)}$ である.

SPG も非ゼロ要素のみの計算で効率的であるが, 複 雑なプログラムであるのでヤコビ係数を計算した後, 既 成のサブルーチンに接続するとよい ${ }^{27)}$. RDM では，70 次を 7 次方程式に還元した連立方程式を解いたが, 残り

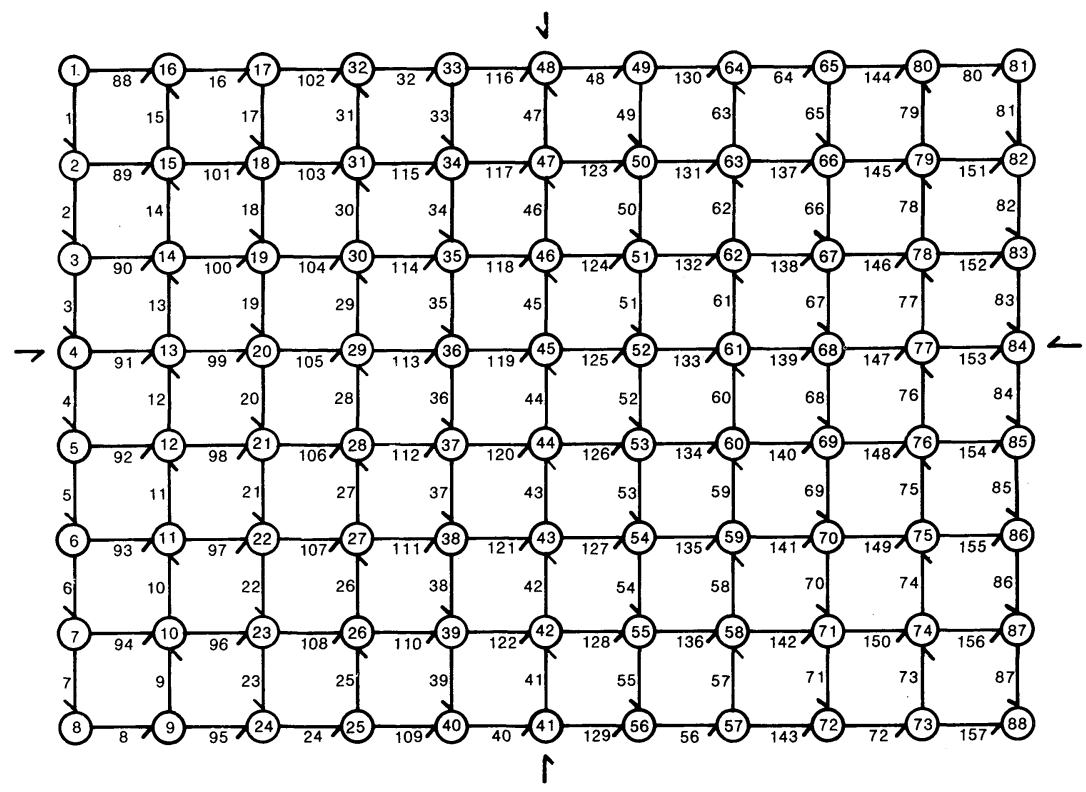

Fig. 2 System 2. 
Table 3 Comparison between Numerical Results with Newton-Raphson Algorithm. SPG SOR RIM

\begin{tabular}{|c|c|c|c|c|}
\hline$I=0$ & $\begin{array}{l}\mathrm{T} \\
\mathrm{P}\end{array}$ & $\begin{array}{r}2 M 55 \mathrm{~S} \\
182.156995\end{array}$ & $\begin{array}{r}3 M 17 \mathrm{~S} \\
182.156995\end{array}$ & $\begin{array}{r}6 \mathrm{M} \mathrm{50} \mathrm{S} \\
182.156995\end{array}$ \\
\hline$I=1$ & $\begin{array}{l}\mathrm{T} \\
\mathrm{P} \\
\mathrm{G}\end{array}$ & $\begin{array}{r}5 M 40 S \\
176.573151 \\
29.47079\end{array}$ & $\begin{array}{c}5 M 56 \mathrm{~S} \\
176,573152 \\
29.47080\end{array}$ & $\begin{array}{r}9 \text { M } 49 \text { S } \\
176.573151 \\
29.47079\end{array}$ \\
\hline$I=2$ & $\begin{array}{l}\mathrm{T} \\
\mathrm{P} \\
\mathrm{G}\end{array}$ & $\begin{array}{r}8 M 25 \mathrm{~S} \\
176.497991 \\
1.733102\end{array}$ & $\begin{array}{c}8 M 25 \mathrm{~S} \\
176.497991 \\
1.733119\end{array}$ & $\begin{array}{c}12 M 48 \mathrm{~S} \\
176.497990 \\
1.733102\end{array}$ \\
\hline $1=3$ & $\begin{array}{l}T \\
P \\
\text { G }\end{array}$ & $\begin{array}{r}11 \text { M } 10 \mathrm{~S} \\
176.497575 \\
0.111809\end{array}$ & $\begin{array}{c}10 \mathrm{M} \mathrm{33} S \\
176.497575 \\
0.111814\end{array}$ & $\begin{array}{c}15 M 47 S \\
176.497576 \\
0.111809\end{array}$ \\
\hline I- 4 & $\begin{array}{l}\mathrm{T} \\
\mathrm{p} \\
\mathrm{G}\end{array}$ & $\begin{array}{r}13 M 55 S \\
176.497575 \\
2.317 D^{-3}\end{array}$ & $\begin{array}{c}12 M \quad 3 \mathrm{~S} \\
176.497575 \\
2.320 \mathrm{D}^{-3}\end{array}$ & $\begin{array}{c}18 \text { M } 46 \mathrm{~s} \\
176.497575 \\
2.317 \mathrm{D}-3\end{array}$ \\
\hline$I=5$ & $\begin{array}{l}T \\
p \\
G\end{array}$ & $\begin{array}{r}16 \mathrm{M} 40 \mathrm{~S} \\
178.497575 \\
1.003 \mathrm{D}-6\end{array}$ & $\begin{array}{c}13 \text { M 11 S } \\
176.497575 \\
9.760 D-5\end{array}$ & $\begin{array}{c}21 \mathrm{M} 45 \mathrm{~S} \\
176.497575 \\
1.003 \mathrm{D}-6\end{array}$ \\
\hline$I=6$ & $\begin{array}{l}T \\
P\end{array}$ & & $\left(w_{c}=1.5\right)$ & \\
\hline
\end{tabular}

Table 4 Numerical result with SOR.

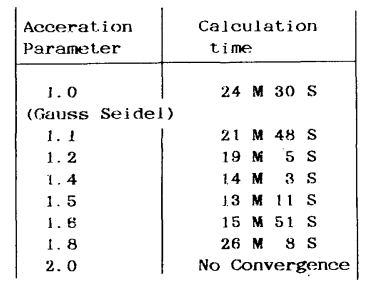

Table 5 Non-linear Optimization problem.

\begin{tabular}{|c|c|c|}
\hline & \multicolumn{2}{|r|}{$\mathrm{CG} 1$} \\
\hline & & (With initial) \\
\hline \multirow[t]{2}{*}{$\mathfrak{i}=0$} & $\mathrm{~T}$ & $4 \mathrm{M} 40 \mathrm{~S}$ \\
\hline & $\mathrm{p}$ & 182.156995 \\
\hline \multirow[t]{2}{*}{$I=10$} & $\mathrm{~T}$ & $12 M i 5 \mathrm{~s}$ \\
\hline & $\mathrm{p}$ & 176. 52170 \\
\hline \multirow[t]{2}{*}{$I=20$} & $\mathrm{~T}$ & $21 \mathrm{M} 37 \mathrm{~S}$ \\
\hline & $\mathrm{P}$ & 178.49773 \\
\hline \multirow[t]{2}{*}{$I \cdot 30$} & $\mathrm{~T}$ & $30 M 51 \mathrm{~S}$ \\
\hline & $\mathrm{P}$ & 176.49758 \\
\hline \multirow[t]{6}{*}{$1-40$} & $T$ & $39 \mathrm{M} 57 \mathrm{~s}$ \\
\hline & $\mathrm{P}$ & 176.49758 \\
\hline & & $I \sim 48$ \\
\hline & $\mathrm{T}$ & $47 \mathrm{M} 1 \mathrm{~S}$ \\
\hline & $\mathrm{P}$ & 176.49758 \\
\hline & & $((2.2612 \mathrm{D}-6))$ \\
\hline
\end{tabular}

CG2

(No initiaj)

(AJ $\left.1-q_{c}^{\prime}-0,5\right)$

$11 \mathrm{M} 46 \mathrm{~S}$ 178. 12935

$20 \mathrm{M} \mathrm{O3} \mathrm{S}$ 176. 56469

28 M 52 S 176. 49802

37 M $37 \quad \mathrm{~S}$ 176. 48759

$I=68$

55 M $36 \mathrm{~s}$ 176. 49758

$((1.77461)-8))$
CKM

(with in:tial) $4 \mathrm{M} 40 \mathrm{~s}$ 185. 156995

25 M $59 \mathrm{~s}$ 177. $33028(44.58)$

46 M $15 \mathrm{~S}$ 176. $87852(15.63)$

64 M 54 $170.68506(6.176)$

83 M $33 \mathrm{~S}$ 176. $62837(3.213)$ $I=140 ?(2 * N G)$

6. 1412 M $30 \mathrm{~S}$ 176. $49845(0.011)$ No convergence
Table 6

\begin{tabular}{lcc}
\hline & Number of Array & $\begin{array}{c}\text { Example } \\
\text { (System 2) }\end{array}$ \\
\hline SPG & $6 \mathrm{NP}+9.5 \mathrm{NG}+3 \mathrm{NE}+3 \mathrm{LW}$ & $\begin{array}{c}4100 \\
(\mathrm{NE}=316, \mathrm{LW}=517)\end{array}$ \\
\hline SOR & $6 \mathrm{NP}+7 \mathrm{NG}+3 \mathrm{NE}$ & $\begin{array}{c}2380 \\
(\mathrm{NE}=316)\end{array}$ \\
\hline $\mathrm{CG} 1$ & $11 \mathrm{NP}+\mathrm{NS}$ & 1810 \\
\hline
\end{tabular}

に特徴があるが，計算時間では，SYG よりは収 束性がよいが他の SPG，SOR，RDM の数倍の 時間を必要とする. CG 2 は，任意な初期値（ $\boldsymbol{q}_{c 1}^{\prime}$ のすべての成分を 0.5 とした）より最小化計算し た. 初期值設定は有効といえる. Table 中の $((\quad))$ 内は，流量ベクトルの真值に対する誤差ノルムで ある。

Table 6 には，1 次元配列を基本とする解法の 必要配列数の目安を示す。

$\mathrm{NE}=$ ヤコビ係数行列の非ゼロ要素の総数, $\mathrm{LW}=$ ガウス法で消去に用いる行列のある列ベク トルの非ゼロ要素数の総和 ${ }^{27)}$.

\section{3. 結 論}

（1）補木流量法と Mesh 流量法の関係をグラ フ理論で定式化できた。

（2）管網の有向グラフで節点・経路・閉路の 番号づけの合理的方法を与え，既約接続行列の データ入力の不必要性, 基本閉路行列の非ゼ口要 素表の作成法と具体例を示し，疎行列演算の効率 化を計り，実用上の指針を与えることができた。

（3）管路の散冕エネルギーの最小化原理に基 づく非線形最小化問題として，定常流解析の計算 アルゴリズムを明示し，Newton-Raphson 法の諸 解法 (SOR, 還元解法, 対称疎行列性を利用し たガウス法等) との比較を大規模管網の計算例を 通して行い，次の点が明らかとなった。

a) 最小の必要配列総数で計算可能である.

b) 計算時間は, 最良と評価し得る諸解法の 2 ４ 倍程度である.

c）最小化による解法としては，閉路エネル ギーの誤差ベクトルの 2 乗ノルムを目的関数とす る方法より，かなり優れている。

以上より，提示した最小化計算アルゴリズムは

の解を求めるときに，2次元配列を用いているのでゼロ 要素の計算を完全には排除しきれていないので，より効 率化し得る. SYG (No pivot) は他の 3 つの解法より, 見劣りする. Table 5 に非線形最小化問題の各解法 (CG 1, CG 2, CRM) の計算結果を示す. CRM は, $2 N G$ (140) 回の燥返し計算でも収束せず，綾の指摘を 裏づけている. CG 1 は, 配列数の節減とベクトル演算
十分実用上の価値がある。

なお，計算はすべて PC 9801 で倍精度計算した。

\section{参 考 文 献}

1) 三野 徹：パイプラインの水理設計（その 3,4$)$, 農業 土木学会誌, 49 (11), pp. 43〜48, (12), pp. 69〜78, 1981.

2) 常松芳昭: 管路水輸送システムのグラフ理論的解析, 土 木学会論文報告集, No. 229, pp. 21 31，1974. 
3）西川稦一・宇土顕彦：大規模管網計算の高速化と管路取 出しモデルによる高精度化, 水道協会雑誌, No. 603, pp. 2〜16, 1984.

4）高桑哲男：閉管路方程式法による配水管網の解析, 水道 協会雑誌, No.485, pp. 16〜26, 1975.

5) Epp, R. and Fowler, A. G. : Efficient Code For SteadyState Flows In Networks, J. of the Hydraulics Div. ASCE, Vol.96, HY 1, pp.43 56, 1970.

6) 高桑哲男: 配水管網の解析之設計, 森北出版, 1978.

7）綾日出教：配水施設のシミュレーションII, 水道協会雑 誌, No. 568, pp. 29 44, 1979.

8) Lemieux, P.F. : Efficient Algorithm For Distribution Networks, J. of the Hydraulics Div., ASCE, Vol.98, HY 11, pp. 1911 1920, 1972.

9) Chandrashekar, M. and Stewart, K. H. : Sparsity Oriented Analysis of Large Pipe Network, Jour. of the Hydraulics Div., ASCE, Vol.101, No. HY 4, pp.341 355, 1974.

10) Maxwell, J.C. : Treatise on electricity and Magnetism, Vol. I, 3 rd ed., p. 407, 1873.

11) Millar, W. : Some General Theorems for Nonlinear Systems Possesing Resistance, Phil. Mag., ( 7 ) 42, pp. 1150 1160, 1951.

12) Birkoff, G. and Diaz, J.B. : Non-linear Network Problems, Quart. Appl. Math., Vol. XII, No.4, pp. 431 443, 1956.

13) Brayton, R.K. and Moser, J.K. : A Theory of Nonlinear Networks I and II , Quart. Appl. Math., Vol. XXII, No. 1 and No. 2, pp. $1 \sim 33$ and pp. $81 \sim 104$, 1964.

14) Onizuka, K. : Potential Function and Stability of Nonlinear Water Distribution Systems, Theoretical and Appl. Mech., Tokyo Univ. Press, Vol.23, pp.375
399, 1975.

15）鬼塚宏太郎：状態空間解析による枝わかれ管路のサージ ング減衰特性の評価, 土木学会論文報告集, 第 262 号, pp. 79 89, 1977.

16) Collins, M., Cooper, L. et al. : Solving the Pipe Network Analysis Problem Using Optimization Techniques, Management Science, Vol.24, No.7, pp. $747 \sim 760,1978$.

17) Kesavan, H. K. and Chandrashekar, M. : Graphtheoretic Models for Pipe Network Analysis, Jour. of the Hydraulics Div., ASCE, Vol.98, No. HY 2, pp.345 364, 1972.

18）前田 渡・伊東正安：現代グラフ理論の基礎，オーム社, 1978.

19) Wood, D. J. and Charles, Carl, Q.A. : Hydraulic Network Analysis Using Linear Theory, Jour. of the Hydraulics Div., ASCE, Vol.98, No. HY 7, pp.1157 1170, 1972.

20）戸川隼人：共役勾配法, 教育出版, 1977.

21）今野 浩-山下 浩: 非線型計画法, 日科技連, 1978.

22）町田東一・小島紀男 : パソコン BASIC 数值計算 II, 東 海大学出版会, 1984.

23) Shamir, Uri. and Howard, Charles, D. D. : Water Distribution System Analysis, Jour. of the Hydraulics Div. , ASCE, Vol. 94, No. HY 1, pp. 19 234, 1968.

24）島田正志：管網系定常流解析の直接解法の問題点につい て, 農業土木学会論文集, No. 116, pp. 41 47, 1985.

25）戸川隼人：マトリクスの数值計算, オーム社, 1971.

26）高桑哲男：配水管網流量計算法に関する研究 II, 水道協 会雑誌, No. 422, pp. 27〜36, 1969.

27）村田健郎：小国 力・唐木幸比古：スーパーコンピュー ター (科学技術計算への適用), 丸善, 1985 .

(1984.9.20 - 受付) 